\title{
K-ras peptide mimotope induces a humoral immune response against G12V K-ras antigen in BALB/c mice
}

\author{
Winfrey Pui Yee Hoo, Pui Yan Siaka, Nur Aqlili Riana Alias ${ }^{\mathrm{b}}$, Jia Jia Wong ${ }^{\mathrm{a}, \mathrm{c}}$, Ee Wern Tan ${ }^{\mathrm{a}, \mathrm{d}}$, Adelene \\ Ai-Lian Song, ${ }^{\text {e,f }}$, Raha Abdul Rahim ${ }^{a, f}$, Lionel Lian Aun In ${ }^{a^{*}}$ \\ ${ }^{a}$ Department of Biotechnology, Faculty of Applied Sciences, UCSI University, Cheras, Wilayah Persekutuan Kuala Lumpur, Malaysia \\ ${ }^{b}$ Department of Cell and Molecular Biology, Faculty of Biotechnology and Biomolecular Sciences, Universiti Putra Malaysia, Selangor, Malaysia \\ 'Department of Biological Sciences, School of Healthcare and Medical Sciences, Sunway University, Petaling Jaya, Selangor, Malaysia \\ ${ }^{d}$ Department of Biological Sciences, School of Science and Technology, Sunway University, Petaling Jaya, Selangor, Malaysia \\ ${ }^{e}$ Department of Microbiology, Faculty of Biotechnology and Biomolecular Sciences, Universiti Putra Malaysia, Selangor, Malaysia \\ ${ }^{f}$ Institute of Bioscience, Universiti Putra Malaysia, UPM Serdang, Selangor, Malaysia
}

Received 31st December 2019 / Accepted 9th June 2020

\begin{abstract}
Background. KRAS mutations are highly prevalent in pancreatic, lung, and colorectal carcinomas with G12V point substitution being one of the most prevalent mutations. While developments of peptide vaccines for $K R A S(+)$ cancers are usually associated with poor immunogenicity, coupling mutant $\mathrm{K}$-ras vaccines with universal $\mathrm{CD} 4^{+}$carrier molecules may enhance its outcome. Additionally, recent immunotherapeutic advances also suggest the possibility of inducing mucosal immunity against cancers using Lactococcus lactis as a live gastrointestinal delivery vehicle. Methods. A region of wild-type Kras peptide was previously modified with a V7D substitution flanking the G12V mutation, generating a $\mathrm{K}$-ras peptide (termed $68-\mathrm{V}$ ) with improved predicted antigenicity. This peptide was fused with a diphtheria toxoid sequence, and cloned into pNZ8048 vector within Lactococcus lactis NZ9000. BALB/c mice were then immunized orally, and then subjected to T/B cells immunophenotyping, as well as IgG and $\operatorname{IgA}$ detection. Results. Modified 68-V K-ras peptide and controls were successfully cloned and detection of His-tagged proteins expressed following induction by nisin was observed. Populations of $\mathrm{CD} 3 \mathrm{CD}^{-} 9^{+}$immune cells increased following immunization of $68-\mathrm{V}$, while $\mathrm{K}$-ras specific-IgG and $-\operatorname{IgA}$ sera titers were elevated compared to wild-type and G12V K-ras controls. Conclusion. 68-V K-ras mimotope was shown to induce humoral-mediated immunity, highlighting the ability of an additional mutation flanking the G12V KRAS mutation to induce B cell activation and production of $\mathrm{K}$-ras specific antibodies, while diphtheria toxoid was unable to stimulate an enhanced response when fused to $68-\mathrm{V}$. Nevertheless, these findings showed that further assessments are required to understand the role of K-ras specific antibodies within a $K R A S(+)$ environment.
\end{abstract}

Keywords: Cancer, diphtheria toxoid, $K R A S$, Lactococcus lactis, mimotope, peptide vaccine

\section{INTRODUCTION}

$K R A S, H R A S$ and $N R A S$ each encodes for small GTPases that makes up the Ras superfamily, which plays a role as molecular switches in the regulation between inactive GDP-bound and active GTP-bound states involved in normal cell signal transduction cascades ( $\mathrm{Lu}$ et al., 2016; Haigis, 2017). Found in approximately $30 \%$ of human cancers, mutations predominantly at

*Author for correspondence: Lionel In Lian Aun, No. 1, Jalan Menara Gading, UCSI Heights, 56000 Cheras, Kuala Lumpur, Malaysia. Email lionelin@ucsiuniversity.edu.my 
codons 12 and/or 13 within the oncogenic KRAS are frequently found in non-small cell lung carcinomas (NSCLCs), colorectal cancers (CRCs), and pancreatic ductal adenocarcinomas (PDACs) (Prior, Lewis \& Mattos, 2012; HerrerosVillanueva et al., 2014; Stephen et al., 2014; McCormick, 2015), with missense mutations in Ras proteins caused by single point mutations disrupting GDP and GTP binding balance (Lu et al., 2016; Haigis, 2017). Altered K-ras proteins are able to reduce the hydrolysis of GTP into GDP or increase the rate of GTP loading, resulting in continuous binding of GTP to K-ras proteins, an active switch that amplifies pro-tumorigenic signaling downstream of the Ras-Raf-MAPK pathway (Lu et al., 2016; Haigis, 2017; Jinesh et al., 2018; McCormick, 2018). Although KRAS oncogene is one of the most commonly found aberrations in cancers, with reports indicating the role of exon $2 \mathrm{KR} A S$ mutations as an important predictive biomarker for the lack of response to anti-EGFR monoclonal antibodies such as panitumumab and cetuximab in metastatic CRCs (Benvenuti et al., 2007; Banck \& Grothey, 2009), minimal advances in KRAS-specific treatments with a successful clinical response have been reported.

While it has since been a major challenge in designing effective therapies for $K R A S(+)$ cancers, peptide vaccine development has been widely studied and the vaccine design incorporates synthetic peptides derived from epitopes of tumor-specific or tumor-associated antigens (TSAs or TAAs). Aside from being relatively easy and inexpensive to produce, as well as having minimal toxicity towards normal cells (Bei \& Scardino, 2010), short peptides of 8 to 10 monomers usually stimulate tumor-specific cytotoxic $\mathrm{T}$ lymphocyte (CTL) responses, while long peptides of up to 16 monomers trigger helper $\mathrm{T}$ cell responses, albeit being insufficient to support progression free survival (Slingluff, 2011; Hirayama \& Nishimura, 2016; Oryazún \& Kobe, 2016). Mimotopes, which are modified mimics of natural epitopes, have been hypothesized to potentially trigger enhanced cellular or humoral responses, being capable of stimulating the secretion of response-specific cytokines, stimulating production of antibodies, having superior MHC affinity and potentially stimulate the development of immunological memory against targeted TAAs/TSAs, thus potentially preventing cancer occurrence or relapse (Sharav, Wiesmüller \& Walden, 2007; Knittelfelder, Riemer \& Jensen-Jarolim, 2009; Buhrman \& Slansky, 2013). Peptide vaccines reported to induce immunogenicity against Ras antigens include: Targovax's TG01 vaccine targeting mutant Ras combination at codons 12 and 13 that has to be co-administered with GM-CSF, and Globeimmune's GI-4000 vaccine delivered by heat-killed recombinant yeast, which targets three different mutant KRAS combinations; both of which have entered Phase I/II clinical trials for PDACs and NSCLCs respectively (Palmer et al., 2017; Chaft et al., 2014; Hartley et al., 2015).

Several studies have reported the incorporation of sequence modifications within tumor antigen-derived peptides to enhance their immunogenicity, among which, includes single amino acid substitution to enhance HLA binding affinity preferably corresponding to $\mathrm{MHC}$ class I molecules (Bei \& Scardino, 2010; Lipford et al., 1995; Pogue et al., 1995; Fikes, 2004). Such modification has been associated with successful immunogenicity enhancement when assessed in vivo (Schreurs et al., 2005; Kumar et al., 2015). Our preliminary study reported on the modification of G12V K-ras peptide via aspartic acid substitution at position 7 within peptide sequence (YKLVVVGAVGVGKSA) from codon 4 to 18 in order to improve the binding of epitopes to MHC class I and II molecules (Ng et al., 2018). Despite highlighting the potency of modified G12V K-ras peptide as an antigenic mimotope in silico, the modified peptide was unable to significantly trigger an immune response against G12V K-ras antigens when tested in vitro. Several other studies have also reported similar findings and have therefore coupled peptides with carrier molecules such as keyhole limpet hemocyanin (Swaminathan et al., 2014), tetanus toxoid (da Silva Antunes et al., 2018), and diphtheria toxoid (Yano et al., 2015; Diethelm-Okita et al., 2000) to improve overall immunogenicity of peptide-based vaccines.

Another exciting aspect of modern day anticancer therapeutic intervention is the use lactic acid bacteria (LAB) as live delivery vehicles of oral vaccines. $L A B$ has the ability to promote both mucosal and systemic immune responses in gutassociated lymphoid tissues (Pellissery \& Nair, 
2013; Azizpour et al., 2016; Israr et al., 2018). In this study, Lactococcus lactis was chosen as the host for the production of mimotopes against $K R A S(+)$ cells as this Gram-positive probiotic bacteria possess advantageous properties such as its generally recognized as safe (GRAS) status, availability of established expression and secretion systems, the absence of inclusion bodies and endotoxins, as well as its non-colonizing nature of the gut. Therefore, this report describes the enhancement and assessment of immune responses triggered by modified G12V K-ras mimotope coupled with $\mathrm{CD}^{+}$epitope sequence of diphtheria toxoid (DT) following oral administration employing a lactococcal live delivery system. Inbred BALB/c mice were used in the immunological assessments of K-ras mimotopes due to the fact that: (i) mouse biology is highly similar to human biology (Mestas \& Hughes, 2004), and (ii) $\mathrm{BALB} / \mathrm{c}$ is a highly established strain for immunological studies which are significant in the development of drugs, peptides or vaccines (Mills et al., 2000).

\section{MATERIALS AND METHODS}

\section{Bacterial strains and plasmid}

In this study, L. lactis NZ9000 (Universiti Putra Malaysia) host cells harboring pNZ8048 plasmids (Universiti Putra Malaysia) were cultured at $30^{\circ} \mathrm{C}$ in M17 broth (Merck, Germany) supplemented with $0.5 \%(\mathrm{w} / \mathrm{v})$ glucose (Chemiz, Malaysia) and $10 \mu \mathrm{g} / \mathrm{ml}$ chloramphenicol (Merck, Germany). Meanwhile, XL-10 GOLD E. coli (Stratagene, USA) host cells were cultured in LB broth (Becton, Dickinson and Company, USA) with at $37^{\circ} \mathrm{C}$. A supplemental file lists the bacteria strains used, as well as the details of recombinant $L$. lactis clones generated in this study [see Supplemental Table S1].

\section{PCR amplification of wtKRAS and site- directed mutagenesis of control mimotope}

Caco-2 human CRC cell line (Universiti Malaya) harboring wtKRAS was cultured in DMEM (Biowest, France) supplemented with 10\% (v/v) FBS (Biowest, France) at $37^{\circ} \mathrm{C}$ with $5 \% \mathrm{CO}_{2}$. Caco-2 total RNA was harvested using the RNeasy Mini Kit (Qiagen, Germany) and cDNA was synthesized using Omniscript RT kit (Qiagen, Germany) with poly-dT primers. First 50 codons of wtKRAS (GenBank Accession Number: M54968.1) was amplified from the cDNA prior to PCR-based site-directed mutagenesis (SDM) to generate mimotope control harboring G12V mutation, tagged with a $6 \mathrm{x}$ histidine sequence as well as incorporation of restriction sites. All PCR amplifications were carried out using $0.02 \mathrm{U} / \mu \mathrm{l}$ Q5 Hi-Fidelity DNA polymerase (New England Biolabs), $2 \mathrm{mM} \mathrm{MgCl}$, $0.2 \mathrm{mM}$ dNTP mix, 0.05 $\mathrm{mM}$ primers and 200-1000 ng template. A supplemental file shows details of the primers used in this study [see Supplemental Table S2].

\section{Synthesizing and generating mimotope oligonucleotides}

Oligonucleotides encoding peptides $68-\mathrm{V}$ (YKLDVVGAVGVGKSA) (Ng et al., 2018) and DT (QSIALSSLMVAQAIPLVGEL) (DiethelmOkita et al., 2000) were synthesized separately in lyophilized pIDT:SMART vectors (Integrated DNA Technologies, USA). Resuspended lyophilized plasmids were transformed into chemically-competent X-10 GOLD E. coli host cells via heat shock method, and selected on LB agar (Becton, Dickinson and Company, USA) with $10 \mu \mathrm{g} / \mathrm{mL}$ ampicillin. Oligonucleotide $68-\mathrm{V}$ and DT were amplified from the plasmids extracted using DNA-spin plasmid extraction kit (iNtRON Biotechnology, Korea), and were fused together via splicing by overlap extension (SOE)PCR.

\section{Cloning recombinant L. lactis and expression of mimotopes}

pNZ8048 vectors were extracted from $L$. lactis NZ9000 using iNtRON DNA-spin plasmid extraction kit according to manufacturer's protocol. A signal peptide, usp45 (Universiti Putra Malaysia) was first amplified and cloned into pNZ8048 between NcoI and SphI recognition sites. Previously amplified wtKR AS, G12V and $68-\mathrm{V}$ mimotopes were then incorporated into pNZ:usp45 between SphI and SpeI recognition sequences, while 68-V:DT mimotope was added between SphI and HindIII recognition sites (Figure 1A). Recombinant plasmids were then electroporated into L. lactis NZ9000 host cells at $2.3 \mathrm{kV}$ at $200 \Omega$ for 5 milliseconds, with minor modifications to the protocol previously 
described (Holo \& Nes, 1989). Minor modifications were made during preparation of electrocompetent cells whereby M17 media supplemented with $0.5 \%(\mathrm{w} / \mathrm{v})$ glucose, $2.5 \%$ $(\mathrm{w} / \mathrm{v})$ glycine and $0.5 \mathrm{M}$ sucrose were used and cells were resuspended in 1/20 culture volume. Transformed samples were selectively grown on M17 agar with $0.5 \mathrm{M}$ sucrose, $0.5 \%$ (w/v) glucose, and $10 \mu \mathrm{g} / \mathrm{ml}$ chloramphenicol, with positive transformants confirmed by colony PCR using vector-specific primers before sequencing. All recombinant $L$. lactis were cultured in M17 broth supplemented with $0.5 \%(\mathrm{w} / \mathrm{v})$ glucose and 10 $\mu \mathrm{g} / \mathrm{mL}$ chloramphenicol, and expressed for 27 hours upon induction with $40 \mathrm{ng} / \mathrm{mL}$ nisin (Sigma-Aldrich, USA) at $\mathrm{OD}_{600}=0.5$.

\section{Western blotting}

Induced cultures were centrifuged at $3,500 \mathrm{~g}$ for 10 minutes, with supernatant fractions precipitated using trichloroacetic acid (Subramaniam et al., 2012) to harvest secreted proteins, while intracellular proteins were harvested from pellets following sonication using a Q500 Sonicator (Qsonica LLC, USA) for a total pulse time of 10 minutes with a 10 and 30 seconds on and off pulse cycle. The harvested protein suspensions were separated in 15\% (w/v) tricine gel at $120 \mathrm{~V}$ for 5 hours, followed by blotting of proteins onto PVDF membrane (Bio-Rad, USA). Blotted membranes were blocked with $1 \%(\mathrm{w} / \mathrm{v})$ BSA before the detection of His-tagged mimotopes using Nickel-NTA conjugate from HisDetector ${ }^{\mathrm{TM}}$ Western blot HRP colorimetric kit (KPL, USA).

\section{Casting recombinant L. lactis in edible films}

Cultures were induced with $40 \mathrm{ng} / \mathrm{mL}$ nisin (Sigma-Aldrich, USA) at $\mathrm{OD}_{600}=0.5$ and expressed for about 4 hours to reach $\mathrm{OD}_{600}=2.8$. Cultures were harvested and casted in films made from 4\% (w/v) sodium alginate (Sigma-Aldrich, USA) with $2 \%$ (w/v) lycoat (Roquette, France), followed by wrapping a $\mathrm{pH}$-dependent coating layer for every $1 \mathrm{mg}$ of recombinant $L$. lactis film $\left(10^{9} \mathrm{cfu}\right)$. The coating layer was formulated with $0.34 \mathrm{M}$ methacrylic acid-ethyl acrylate copolymer (Sigma-Aldrich, USA), $22.6 \mathrm{mM}$ triethyl citrate (Sigma-Aldrich, USA), $69.2 \mathrm{mM}$ talcum powder (Zulat Pharmacy Pte Ltd, Malaysia) and $62.6 \mathrm{mM}$ titanium (IV) oxide (Sigma-Aldrich, USA) dissolved in diluent of water, $50 \% \quad(\mathrm{w} / \mathrm{v})$ isopropanol and $35 \%(\mathrm{v} / \mathrm{v})$ acetone. The coating solution was sieved and the filtrate was poured into a petri dish and placed into a dryer for 2 hours before used.

\section{Experimental animals}

A total of twenty female 4 weeks old BALB/c mice were obtained from Animal Resource Unit, Universiti Putra Malaysia, and housed at the Laboratory of Vaccines and Immunotherapeutics (LIVES) at Comparative Medicine and Technology Unit (COMeT). Meanwhile, all husbandry and care of animals were carried out in accordance to: (i) the ARRIVE guidelines under Institutional Animal Care and Use Committee ethics approval (UPM IACUC approval number: UPM/IACUC/AUP-R038/2017), and

Animal Welfare Act 2015 (Act 772), Malaysia. $\mathrm{BALB} / \mathrm{c}$ mice were randomly housed in groups of four inside plastic cages with access to food and water ad libitum, while corn cobs were used as bedding materials. Housing facility was wellventilated and regulated at $25^{\circ} \mathrm{C}$, followed by acclimatization of mice to the housing facility for two weeks. Mice were monitored daily for health status and mice weighed (mean \pm standard deviation) $19.64 \pm 1.16$ grams at the start of the experiments, while any adverse events were not observed. Groups of BALB/c mice $(n=4)$ were each randomly subjected to PBS and different recombinant $L$. lactis actively expressing K-ras mimotopes. Supplemental Table S3 includes the completed ARRIVE guidelines checklist.

\section{Oral immunization in $B A L B / c$ mice}

Groups of four female 6-8 weeks old immunocompetent $\mathrm{BALB} / \mathrm{c}$ mice were orally immunized twice with $1 \mathrm{mg}$ of respective recombinant $L$. lactis (pNZ:usp45:wtKRAS, pNZ:usp45:G12V, pNZ:usp45:68-V, and pNZ:usp45:68-V:DT) films and $1 \times$ PBS, pH 7.4 (negative control). All films were fed with a Torpac's size M dosing syringe, while PBS was fed using $1.0 \mathrm{ml}$ syringe with 22 -gauge $\times 1.0$ inch feeding needle. Primary immunization was performed on day 1, with two following booster feedings administered at one-week intervals (days 7 and 14). 


\section{Isolation of blood, sera and lower GI wash samples}

Aesthetic procedures were performed prior to all sample collections. Administration was performed intraperitoneally with $20.0 \mu \mathrm{L}$ of ketamine/xylazine cocktail (93.33 $\mathrm{mg} / \mathrm{kg}$ ketamine and $1.33 \mathrm{mg} / \mathrm{kg}$ xylazine) per $20.0 \mathrm{~g}$ of mice body weight, using a 30 -gauge needle. The anesthesia cocktail gave a numbing onset of more than 5 minutes, which can be verified by toe pinch. All sites of injections were cleaned with $70 \%$ (v/v) ethanol prior to any invasive procedures. Mice were anaesthetized with ketamine/xylazil cocktail (Vetoquinol, UK/ Indian Immunologicals Limited, India), followed by whole blood collection: prior to the primary immunization (day 0) by retro-orbital bleeding, and post-euthanization (day 22) by cardiac puncture. Retro-orbital bleeding was performed by gently pressing down with the thumb and forefinger in the occipital area to pull the skin backwards, and slowly inserting a nonheparinized micro-hematocrit capillary tube medially through the conjunctiva on the inner side of the ocular cavity, whereby blood rushed into the tube was collected (Shimizu, 2004). Meanwhile, cardiac puncture was performed using $1 \mathrm{~mL}$ syringe and a 22 gauge needle, whereby needle was pushed vertically below the sternum into the heart for maximum amount of blood collection. Sera were also centrifuged separately at 3,000 $g$ for 15 minutes before storing at $-20^{\circ} \mathrm{C}$. Mice were then euthanized physically by cervical dislocation before the mice recovered from anesthetic conditions and this choice of euthanasia was chosen for immediate painless death after performing cardiac puncture. Cervical dislocation was performed by placing thumb and forefinger behind the base of the anesthetized mouse's skull and pulling back sharply on the tail at a $30^{\circ}$ angle, which damaged the spinal cord and thereby increase the efficacy of the technique as reported by (Carbone et al., 2012). Lower GI tracts were removed and intestinal washes were collected by flushing mice intestines with $3 \mathrm{~mL}$ of 1X PBS, pH 7.4 with $1 \mathrm{mM}$ PMSF. After solution was allowed to stand for about 10 minutes, intestinal washes were centrifuged at 3,000 g, at $4^{\circ} \mathrm{C}$ for 10 minutes to remove solid particles and stools.

\section{Cell surface staining for detection of $T$ and $B$ cell populations}

Procedures on cell surface immunofluorescent staining of whole blood was referred according to BioLegend's protocol (BioLegend, 2018). Every $100 \mu \mathrm{L}$ of anti-coagulated whole blood sample was pre-incubated on ice with $1 \mu \mathrm{g}$ of purified anti-mouse CD16/32 (BioLegend ${ }^{\circledR}$, USA) to block Fc receptors prior to staining. Cell surface staining was performed on mice whole blood using: $0.125 \mu \mathrm{g}$ of Brilliant Violet 421-conjugated anti-mouse CD3, $0.125 \mu \mathrm{g}$ of APC/Fire 750conjugated anti-mouse CD $4,0.25 \mu \mathrm{g}$ of Brilliant Violet 510-conjugated anti-mouse CD8a, 0.0625 $\mu \mathrm{g}$ of APC-conjugated anti-mouse CD19, $0.15 \mu \mathrm{g}$ of Brilliant Violet 605-conjugated anti-mouse CD25, and $0.125 \mu \mathrm{g}$ of PerCP/Cy5.5-conjugated anti-mouse CD335 antibodies (BioLegend $\AA$, USA), for every $100.0 \mu \mathrm{L}$ of whole blood. After staining using fluorochrome-conjugated antibodies, red blood cells (RBCs) were lysed with 1X RBC lysis buffer $(0.155 \mathrm{M}$ ammonium chloride, $0.012 \mathrm{M}$ sodium hydrogen carbonate and $0.1 \mathrm{mM}$ EDTA, adjusted to $\mathrm{pH} 7.3$ ). Every stained sample was suspended in $400 \mu \mathrm{L}$ of Cell

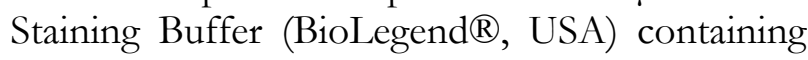
$0.125 \mu \mathrm{g} / \mathrm{mL}$ propidium iodide staining solution (BD Pharmingen $^{\mathrm{TM}}$, USA), followed by sample acquisition using CytoFLEX $S$ flow cytometer (Beckman Coulter, USA). Data were reported as mean percentage \pm standard deviation of three biological replicates, and Student's paired and unpaired T-test were also performed to measure the significant differences.

\section{Assaying for mimotope-specific $\operatorname{Ig} G$ and $\operatorname{IgA}$ responses}

Cross-reactivity test was validated prior to indirect ELISA to detect mimotope-specific IgG and IgA. Assessments were first performed by coating 100 $\mu \mathrm{L}$ of each mimotope $(5 \mu \mathrm{g} / \mathrm{mL})$ diluted in $1 \mathrm{X}$ PBS, pH 7.4 into MaxiBinding microtiter plates (SPL Life Sciences, Korea). Plates were incubated overnight at $4{ }^{\circ} \mathrm{C}$ and blocked with $2 \%(\mathrm{w} / \mathrm{v})$ skim milk. After diluting each mouse serum in the blocking buffer at 1:10, the diluted sera and undiluted intestinal washes were added into respective wells for 2-hour incubation. Mimotope-bound IgGs or IgAs were then captured using HRP-labeled goat anti-mouse IgG (Santa Cruz Biotechnology, USA) or HRP-labeled 
goat anti-mouse $\operatorname{IgA}$ (Invitrogen, USA), which were diluted at 1:12,500 and 1:4,000 respectively. Detection was performed using TMB substrate solution (Elabscience, USA) and stopped by the addition of $2 \mathrm{~N} \mathrm{H}_{2} \mathrm{SO}_{4}$ before measuring absorbance at $450 \mathrm{~nm}$ using FLUOstar ${ }^{\circledR}$ Omega (BMG LABTECH GmbH, Germany). All samples and controls were assayed in duplicates, and all normalized mean data were expressed as net absorbance by subtracting mean absorbance of non-coated wells and no sample controls. IgG and $\operatorname{IgA}$ concentrations were calculated by interpolation from a standard curve and expressed as mean normalized IgG or IgA concentration \pm standard deviation. Differences between preimmunization and post-euthanization were analyzed using Student's paired t-test, while independent samples T-tests were also performed between mice groups, with a $p$-value $\leq 0.05\left(^{*}\right)$ threshold representing statistically significant differences.

\section{RESULTS}

\section{L. lactis NZ9000 as a host for expression and extracellular secretion of mutated $K$-ras mimotopes}

Figure 1B shows colony PCR screening of positive L. lactis NZ9000 transformants using pNZ8048-specific primers flanking the insert. Colony PCR amplicons of transformed pNZ:usp45:wtKRAS, pNZ:usp45:G12V, pNZ:usp45:68-V and pNZ:usp45:68-V:DT showed positive band sizes of $437 \mathrm{bp}, 437 \mathrm{bp}, 335$ bp and 401 bp respectively, while 198 bp bands represent amplicons of vector without the desired insert (data not shown). Undesired mutations were absent in the sequencing analysis of positive transformants (data not shown), indicating that the sequences are in frame and would not affect subsequent downstream expression of recombinant $L$. lactis. Owing to the relatively low molecular weight of target peptides, tricine gels were used to provide better resolution during the separation and detection. K-ras mimotopes were successfully expressed and were confirmed by His-tag detection via Western blotting, with
usp45:wtKRAS and usp45:G12V mimotope controls having sizes of $9.7 \mathrm{kDA}$, while usp45:68$\mathrm{V}$ and usp45:68-V:DT mimotopes were $5.7 \mathrm{kDa}$ and $9.0 \mathrm{kDa}$ respectively (Figure 1C). Western blot of both intracellular and extracellular protein fractions, with nisin concentration at $40 \mathrm{ng} / \mathrm{mL}$ being optimal for maximal expression of Histagged mimotopes after 6 hours of induction are also shown (Figure 1C).

\section{Exposure to recombinant L. lactis expressing 68-V stimulates $B$ cell production}

Provoking either antigen-specific cell-mediated or humoral immune response requires stimulation from effector helper $\mathrm{T}$ cells $\left(\mathrm{CD} 3^{+} \mathrm{CD} 4^{+}\right)$, and immunization with recombinant $L$. lactis expressing K-ras mimotopes were unable to elevate a significant $\mathrm{CD}^{+} \mathrm{CD}^{+}$response (Figure $2 \mathrm{~A})$. This was presumably due to late sampling of sera at 7-days post-second booster, resulting in the inability to capture the changes in $\mathrm{T}$ helper population. Assessing $\mathrm{CD}^{+} \mathrm{CD}^{+}$will determine a cell-mediated immune response, and Figure $2 \mathrm{~B}$ shows that there was no stimulation of CTLs in mice peripheral blood. While a fluctuation in $\mathrm{CD} 3{ }^{-} \mathrm{CD} 19^{+}$response was detected in mice peripheral blood immunized with recombinant $L$. lactis expressing $68-\mathrm{V}$ and $68-\mathrm{V}: \mathrm{DT}$ mimotopes compared to wild-type K-ras and G12V controls, this elevation was found to be statistically insignificant (Figure 2C). Nevertheless, such minute elevations still suggest the possible potential of $68-\mathrm{V}$ K-ras mimotope to induce a humoral immunity, while coupling $68-\mathrm{V}$ with DT failed to significantly improve stimulation of $\mathrm{CD}^{+}$response, presumably due to epitope masking of $68-\mathrm{V}$ by the more prominent and antigenic DT epitope. Meanwhile, Figure 2D suggest that $\mathrm{CD}^{-} \mathrm{CD} 19^{-} \mathrm{CD} 335^{+}$(NK cell) populations were triggered by wild-type and G12V K-ras controls instead of $68-\mathrm{V}$ and 68V:DT K-ras mimotopes. As NK cells are part of the innate system that induces non-specific immunity against invading pathogens (Aziz \& Bonavida, 2016), the variations in NK cell population may be triggered by the presence of $L$. lactis, which constitutes the K-ras live delivery system. 
$\mathbf{A}$
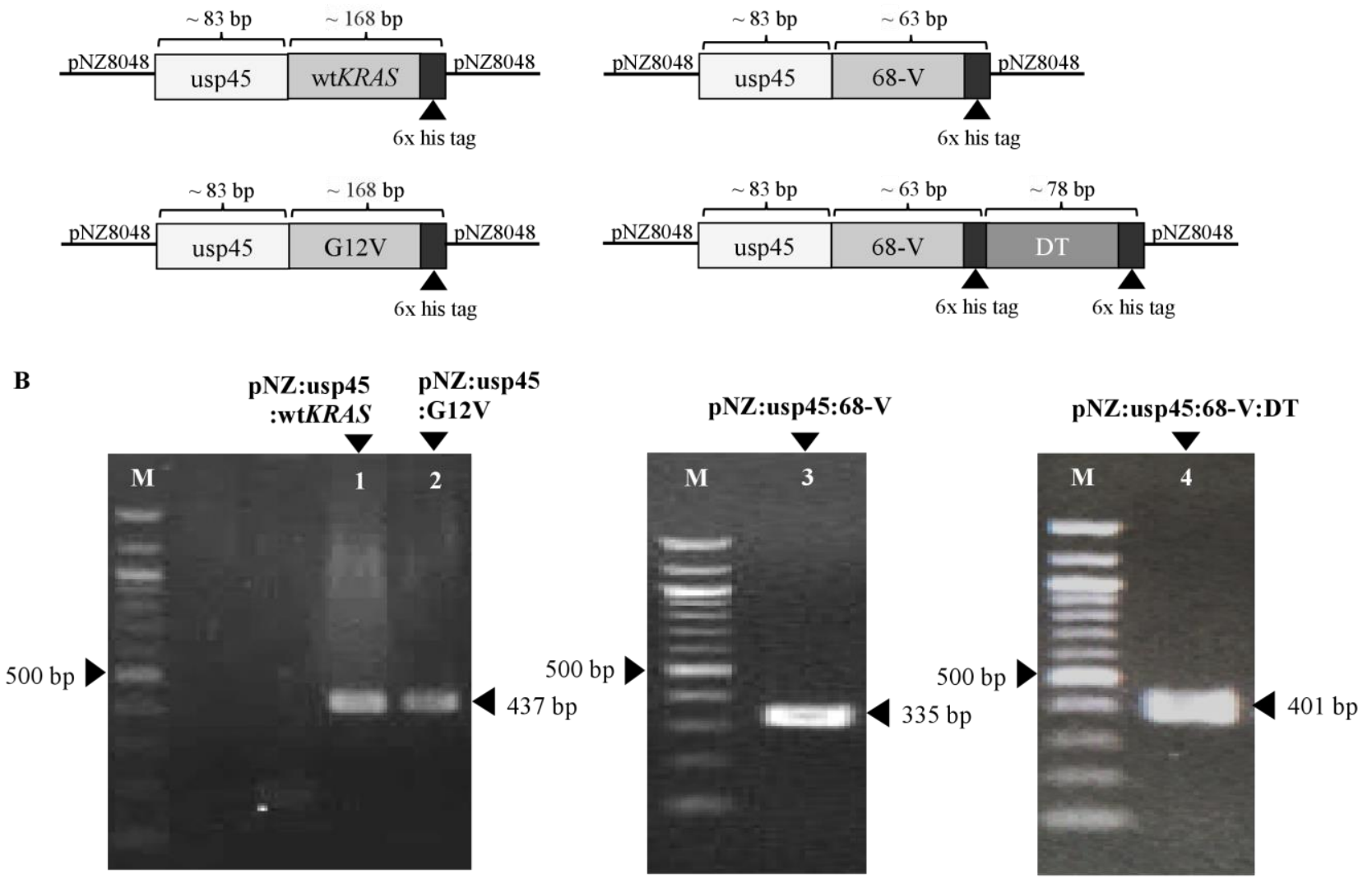

C

usp45:wtKRAS
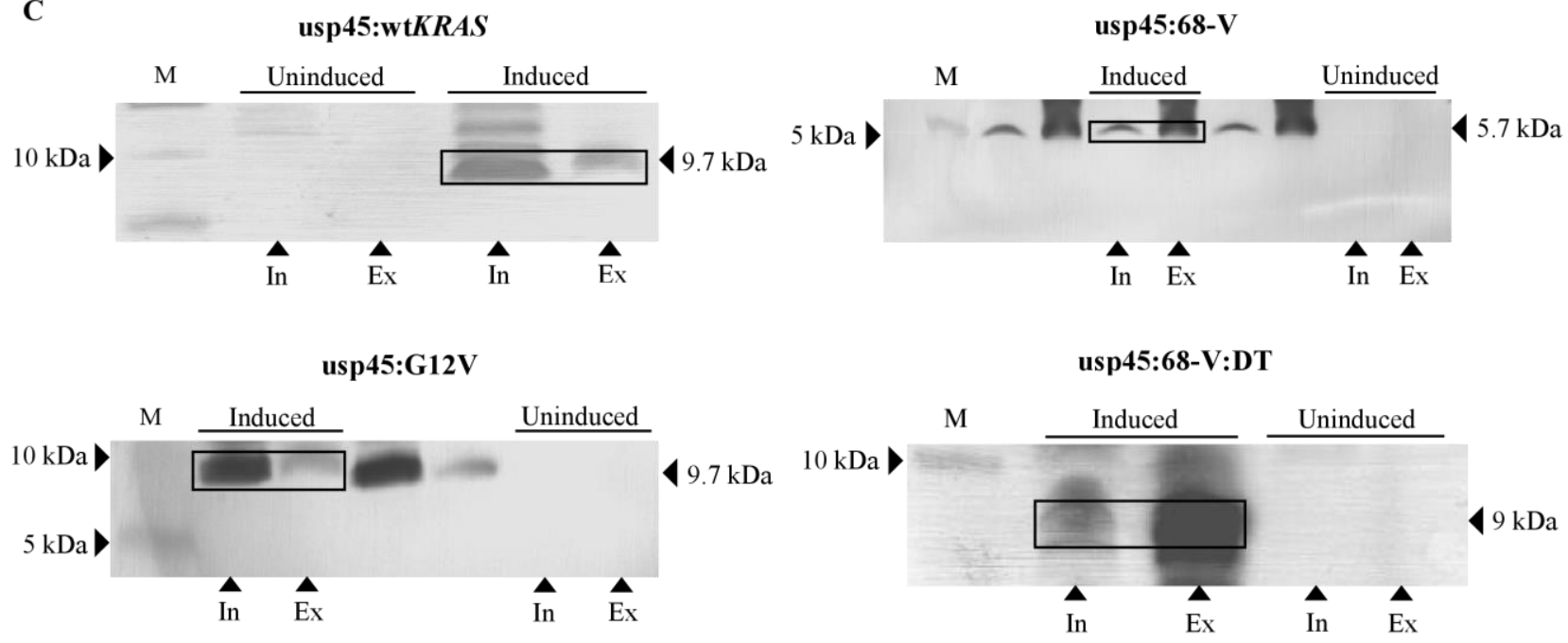

Figure 1. Recombinant $L$. lactis expressing 68-V and 68-V:DT mimotopes and their corresponding wt KR AS and G12V KRAS controls. (A) Graphical map of pNZ:usp45:wtKRAS, pNZ:usp45:G12V, pNZ:usp45:68-V, and pNZ:usp45:68-V:DT. (B) Positive transformants of pNZ:usp45:wtKRAS, pNZ:usp45:G12V, pNZ:usp45:68-V, and pNZ:usp45:68-V:DT. (C) His-tag detection of expressed usp45:wtKRAS, usp45:G12V, usp45:68-V, and usp45:68-V:DT mimotopes. Colony PCR was performed using pNZ8048-specific primers flanking the inserts, while western blotting was performed using Ni-NTA conjugates. M, marker; In, intracellular protein; Ex, extracellular protein; usp45, an extracellular secretion signal peptide; DT, diphtheria toxoid. 


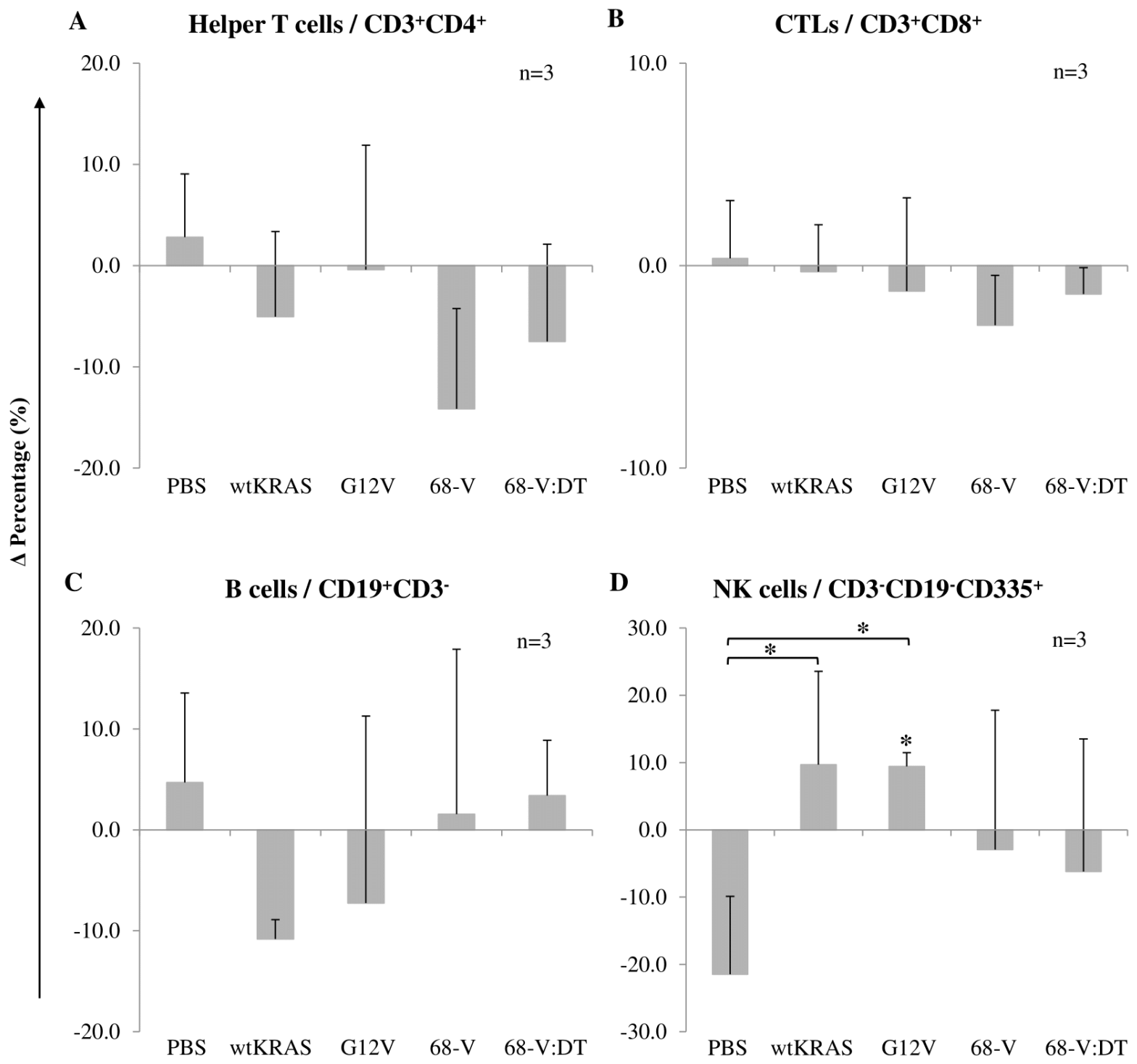

Figure 2. Immunophenotyping profile of mice whole blood after oral immunization of recombinant $L$. lactis expressing $\mathrm{K}$-ras controls (wtKRAS, G12V) and $\mathrm{K}$-ras mimotopes $(68-\mathrm{V}$, 68V:DT). Charts display change $(\Delta)$ in percentage of immune cell populations: (A) helper T cells / $\mathrm{CD}^{+} \mathrm{CD}^{+}$, (B) cytotoxic T lymphocytes $/ \mathrm{CD}^{+} \mathrm{CD}^{2}{ }^{+}$, (C) B cells / CD3 CD19 ${ }^{+}$, and (D) NK cells / CD $3{ }^{-} \mathrm{CD} 19^{-} \mathrm{CD} 335^{+}$. Negative control group comprises of mice fed with PBS. Mice whole blood samples were harvested at day 0 (pre-immunization) and day 22 (post-euthanasia), represented by grey and black bars respectively. All data are presented as change $(\Delta)$ in percentage $(\%)$ of immune cell populations between pre-immunized and post-euthanized mice whole blood. Data were reported in relative mean values \pm standard deviation and data of $p$-value $\leq 0.05\left(^{*}\right)$ is denoted as statistically significant.

Probiotic bacteria have been reported to enhance innate immunity involving NK cell activity, though there is no evidence on the effect of acquired immunity that follows (Calder, 2013). According to these data [see Supplemental Data S1], immunophenotyping of mice whole blood further confirmed the inability of $68-\mathrm{V}$ K-Ras mimotope to stimulate a CTL response.
pNZ.usp45:68-V elicits $G 12 V \mathrm{~K}$-ras specific IgG-and IgA-mediated response in $B A L B / c$ mice sera

Mutated K-ras specific IgG and IgA levels in mice sera between pre-immunization (day 0 ) and posteuthanization (day 22) indicated that pNZ:usp45:68-V was able to elevate both antigen-specific IgG-mediated ( $p$-value $\leq 0.05$ ) and mucosal immune responses $(p$-value $\geq 0.05)$ 
(Figure 3A and 3C). On the other hand, pNZ:usp45:68-V:DT failed to elicit significant IgG or IgA responses, while low to undetectable levels of $\operatorname{Ig} G$ and $\operatorname{IgA}$ were detected in mice sera immunized with recombinant $L$. lactis expressing G12V mimotope control ( $p$-value $\geq 0.05)$. In addition to that, there was little to no detectable IgG response at either time for negative control groups (PBS and wtKR AS). Assessment of crossreactivity in Figure 3B shows that pNZ:usp45:68$\mathrm{V}$ sera samples were highly reactive across all $\mathrm{K}$ - ras antigens compared to other immunized sera counterparts. On the other hand, crossreactivities were not detected between mimotopes and $\operatorname{IgA}$ across all mice intestinal wash samples (Figure 3D). These cross-reactivity tests suggest the specificity of $\operatorname{IgG}$ antibodies raised by $68-\mathrm{V}$ mimotope to target G12V KRAS(+) tumor cells with a cross reaction against wtKR $A S$ is not desirable. Supplemental Data S2 includes the data obtained from the ELISAs performed.

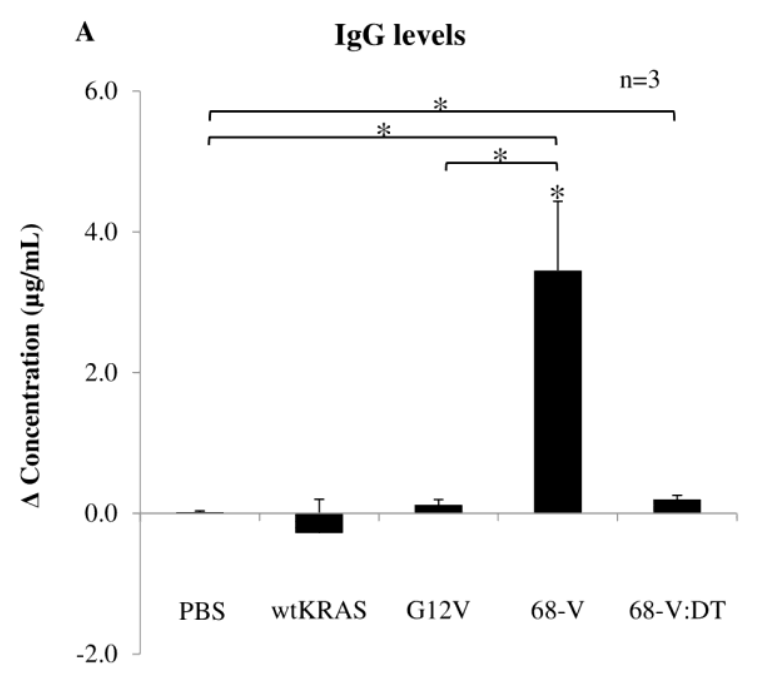

B IgG cross-reactivity

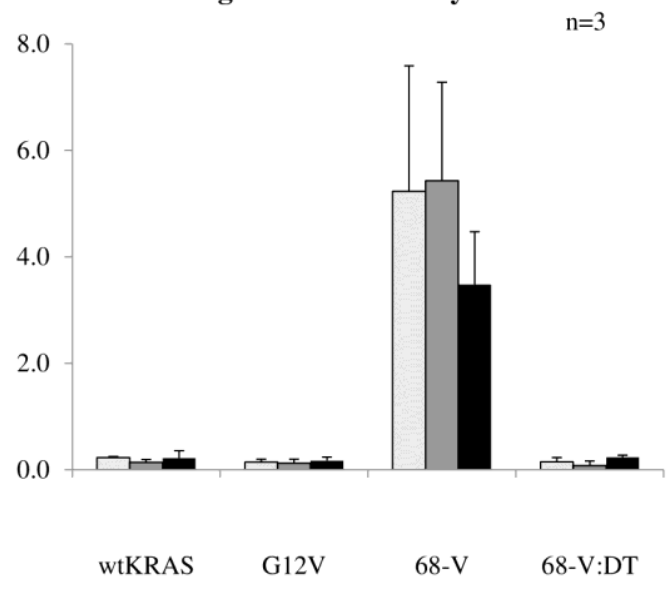

D

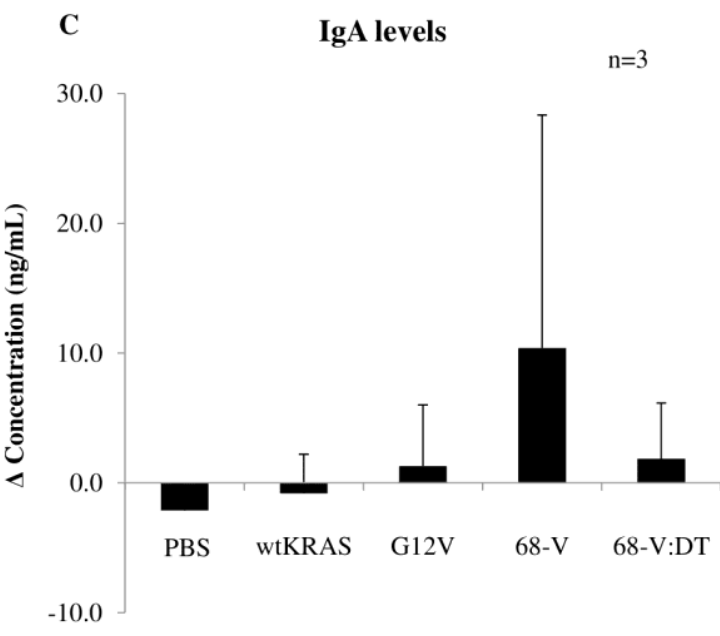

20.0

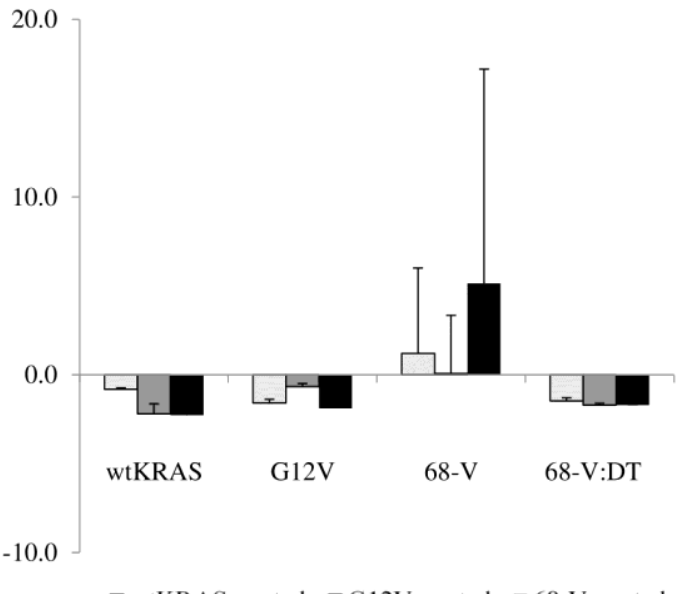

口wtKRAS-coated $\square \mathrm{G} 12 \mathrm{~V}$-coated $\boldsymbol{\square} 68$-V-coated

Figure 3. Mice sera and intestinal washes were assayed for IgG and IgA levels respectively after oral immunization of recombinant $L$. lactis expressing $\mathrm{K}$-ras controls (wtKRAS, G12V) and K-ras mimotopes $(68-\mathrm{V}, 68-\mathrm{V}: \mathrm{DT})$. Charts displayed change $(\Delta)$ in concentrations of: (A) IgG levels for all samples (B) IgG cross-reactivity test, (C) IgA levels for all samples, and (D) $\operatorname{IgA}$ cross-reactivity test. Mice whole blood samples were harvested at day 0 (pre-immunization) and day 22 (post-euthanasia), while mice group fed with PBS was used as negative control. All data are presented as change in $\operatorname{IgG}$ or $\operatorname{IgA}$ concentrations $(\mathrm{ng} / \mathrm{mL}$ ) between pre-immunized and post-euthanized mice sera. Data were reported in mean values \pm standard deviation and data of $p$-value $\leq 0.05\left(^{*}\right)$ is denoted as statistically significant when compared against PBS and G12V control groups. 


\section{DISCUSSION}

While there were studies which have reported on immunized mice with engineered $L$. lactis expressing: E7 antigen against HPV-16-induced cervical cancers (Bermúdez-Humarán et al., 2015), and carcinoembryonic antigen against colon cancer in mice (Zhang et al., 2016), there was yet any attempt on engineering $L$. lactis to target $K R A S(+)$ cancers. With an established safety profile in the food industry, L. lactis is widely used in production of dairy products and its use has been extended into biomedical applications in the recent years (Bahey-El-Din \& Gahan, 2011; Song et al., 2017). Besides low levels of native exoproteins makes $L$. lactis a more desired strain compared to $E$. coli for expression and oral delivery of heterologous proteins (Bahey-El-Din \& Gahan, 2011; Azizpour et al., 2017). Additionally, the non-invasive, non-pathogenic, non-colonising and non-commensal nature of $L$. lactis will not cause high risk in triggering immunotolerance or many unwanted side effects when used in long term (Bahey-El-Din and Gahan 2011; Sasan et al., 2011), while the ability of $L$. lactis to extracellularly secrete recombinant proteins will ease all the downstream processing steps (Jørgensen et al., 2013). In this study, the modified mutant G12V K-ras mimotope was successfully fused with DT and inserted at the cloning site downstream of Pnis $A$ promoter and usp45 signal peptide within the L. lactis cloning and expression vector. Expressions of K-ras mimotopes from positive transformants selectively resistant to chloramphenicol were also detected when induced with addition of subinhibitory amounts of nisin. Nisin is able to trigger transcription of Pnis $A$ promoter within the vector to express the $\mathrm{K}$-ras mimotope, and is then secreted extracelullarly with the help of a signal peptide, which is an added advantage when recombinant $L$. lactis is used as an oral live vaccine host (Bahey-El-Din \& Gahan, 2011).

Even though $L$. lactis is able to induce high expression levels of proteins and only produce a single extracellular housekeeping protease (Poquet et al., 2000), its gastrointestinal survival rate is strain-dependent, thus oral immunization becomes a challenge as this affects its ability to deliver expressed proteins into the GI tract for significant induction of host mucosal and systemic immune responses. L. lactis subsp. cremoris is known to have poor tolerance towards low gastric $\mathrm{pH}$ and intestinal bile salts (Nomura et al., 1999; Kimoto et al., 2003), therefore approaches via encapsulation (Divya \& Nampoothiri, 2015) or packaging in entericcoated mini-capsules (Lei et al., 2010) have been established to protect $L$. lactis against sensitive gastrointestinal environment. Enteric-coated polymer was used in this study to protect recombinant $L$. lactis from low $\mathrm{pH}$ degradation and upon exposure to neutral $\mathrm{pH}$ environment at the lower GI tract, the enteric-coated polymer breaks down and exposes recombinant $L$. lactis casted on alginate film (Dea-Ayuela et al., 2006). The mucoadhesive properties of the alginate film will allow recombinant $L$. lactis to adhere to the mucosal surface and trigger host immunity towards $K R A S(+)$ antigens.

Efficacy of a peptide vaccine in triggering an immune response in host either via a cellmediated or humoral response relies on its animal in vivo assessment before advancing into clinical trials. In this study, the use of inbred BALB/c mice offers consistency in terms of results compared to outbred models due to consistent genetic background and lesser phenotypic variability (Vaickus et al., 2010); and since sex gender was not crucial in this study, female mice were used over male mice owing to their less aggressive nature. Mice and humans were known to be somewhat similar in terms of immune system, genetics and components (Mestas \& Hughes, 2004), thus the choice of animals is especially important as findings using immunocompetent $\mathrm{BALB} / \mathrm{c}$ mice will highly reflect to human biology. The immunological in vitro data ( $\mathrm{Ng}$ et al., 2018) has shortlisted only the potential mutant G12V K-ras vaccine candidate, thus vastly reducing the number of mice groups needed in this study and this approach is in line with "UPM Policy and Code of Practice for the Care and Use of Animal for Scientific Purposes".

Immunophenotyping of mice whole blood has confirmed the inability of $68-\mathrm{V}$ K-ras mimotope to stimulate a CTL response, which is a preferable response in cancer vaccine design. Recombinant $L$. lactis expressing $68-\mathrm{V}$ K-ras mimotope was also shown to elevate K-ras specific $\operatorname{IgG}$ and $\operatorname{IgA}$ levels. Our findings 
therefore suggested that a modification within the mutant K-ras peptide via an amino acid substitution flanking the mutation site is able to enhance its B cell epitope binding affinity, thus mediating a humoral response through activation of plasma cells, which subsequently produce immunoglobulins against mutant G12V K-ras antigens. Using $L$. lactis as the vehicle for GI delivery provokes the immune system to secrete mucosal K-ras-specific IgAs acting as a first line of defense, which is advantageous when targeting tumors found along mucosal surfaces (Dechant \& Valerius, 2001; Ludvigsson et al., 2015). DT fused to the modified mutant G12V K-ras mimotope, on the other hand, failed to stimulate significant induction of immune responses higher than that of $68-\mathrm{V}$ mimotope alone, and this also suggest that the $\mathrm{CD}^{+}$epitope sequence of DT was unable to enhance immunity of its conjugated epitope in mice as compared to human subjects in the study reported by (Diethelm-Okita et al., 2000), probably due to the fact that their human subjects include those that were previously boosted by diphtheria vaccination. There is also the possibility of epitope masking being involved, whereby magnitude of an antibody or immune response to the epitope is reduced when epitope was bound to pre-existing antibodies or antibodies already generated during the immune response triggered following immunization. A study by (Zarnitsyna et al., 2015) has previously demonstrated that the epitope masking model of $\mathrm{HA}$ antigen results in the reduction of primary immune response, while removal of epitope masking from the model reflects an opposite response. In addition, the unknown effect size in sample size estimation would require a follow up study to include a larger sample size to detect an association and reduce the margin of error between samples which will in turn improve the accuracy of results obtained (Kadam \& Bhalerao, 2010).

Majority of peptide vaccines predicted with high binding affinity to $\mathrm{MHC}$ molecules were able to stimulate infiltration of CTLs and induce tumor cell killing with the purpose of eradicating antigen specific tumor cells in cancer treatment (Sahin \& Türeci, 2018). The 68-V mimotope, although predicted with high binding affinity towards human MHC molecules, it was also previously predicted that it has average binding affinity towards mouse MHC molecules (Ng et al., 2018). These suggest that $68-\mathrm{V}$ mimotope has poor CTL recognition in mice, which is not a preferable immune response in cancer treatment; however, humoral response induced by $68-\mathrm{V}$ mimotope would shift the direction of a cancer treatment to a B cell-based anti-cancer immunity. Peptide vaccines that induce tumor-specific $B$ cell responses will first initiate Th activation upon presentation of antigen-bound MHC class II. The following $\mathrm{B}$ cell signaling produces tumor-specific antibodies that induce passive humoral immunity via antibody-dependent cellular cytotoxicity, antibody dependent cellular phagocytosis or complement-dependent cytotoxicity (Kametani et al., 2015; Kaumaya, 2015; Yuen, Demissie \& Pillai, 2016). An example of a study by (Foy et al., 2013) had demonstrated the ability of B cell epitope vaccine to induce EGFR-specific anti-tumor immunity in mice. B cells can also play a role in tumor immunosuppression; therefore, one must distinguish between different $B$ cell subpopulations to understand the efficacy of a peptide vaccine to promote tumor regression (Yuen, Demissie \& Pillai, 2016; Li, Yuan \& Deng, 2016).

\section{CONCLUSION}

Overall, this study has demonstrated that the 68$\mathrm{V}$ K-ras vaccine with an additional mutation (V7D) flanking the native G12V KRAS mutation is able to induce activation of $\mathrm{B}$ cell signaling and production of anti-K-ras specific B cells. Further tumor regression assessments concerning the efficacy of this mimotope vaccine within a $K R A S(+)$ tumor environment is currently underway. Distribution study of the live vaccine can also be performed via imaging to observe the delivery of the labeled live vaccine to the targeted mucosal region of the test subjects, while dosageresponse kinetic can be evaluated to determine the efficacy and safety of the live vaccine. Moving forward, immunogenicity of this $\mathrm{K}$-ras vaccine could also be further enhanced by other means including, but not limited to, emulsification, multimerization or fusion with other adjuvants and carrier molecules. 


\section{ACKNOWLEDGEMENTS}

We thank Kees Leenhouts from University of Groningen for gifting us the original pNZ8048 vector and $L$. lactis NZ9000 strain. In addition, Caco-2 human CRC cell line was a kind gift from Dr. Leong Kok Hoong from Faculty of Medicine at Universiti Malaya, and was originally purchased from Axon Scientific Sdn. Bhd., Malaysia. This study was supported by grants from the Ministry of Higher Education (MOHE) through the Fundamental Research Grant Scheme (FRGS/1/2017/STG05/UCSI/03/2), the Ministry of Science Technology and Innovation (MOSTI) (02-02-22-SF0011) and the UCSI University Pioneer Scientist Initiative Fund (PSIF) (Proj-In-FAS-061). The views expressed are those of the authors. The funders had no role in the planning, execution or analysis of the work.

\section{REFERENCES}

Aziz, N., \& Bonavida, B. 2016. Activation of natural killer cells by probiotics. Forum on Immunopathological Diseases and Therapentics 7(1-2): 41-55.

Azizpour, M., Hosseini, S. D., Jafari, P., \& Akbary, N. 2016. Lactococcus lactis as a live delivery vector. Vaccine Research 3(34): 39-43.

Azizpour, M., Hosseini, S. D., Jafari, P., \& Akbary, N. 2017. Lactococcus lactis: a new strategy for vaccination. Avicenna Journal of Medical Biotechnology 9(4): 163-168.

Bahey-El-Din, M., \& Gahan, C. G. M. 2011. Lactococcus lactis-based vaccines: current status and future perspectives. Human Vaccines 7(1): 106-109.

Banck, M. S., \& Grothey, A. 2009. Biomarkers of resistance to epidermal growth factor receptor monoclonal antibodies in patients with metastatic colorectal cancer. Clinical Cancer Research 15(24): 7492-7501.

Bei, R., \& Scardino, A. 2010. TAA polyepitope DNA-based vaccines: a potential tool for cancer therapy. Journal of Biomedicine and Biotechnology 2010: 102758.

Benvenuti, S., Sartore-Bianchi, A., Di Nicolantonio, F., Zanon, C., Moroni, M., Veronese, S., Siena, S., \& Bardelli, A. 2007. Oncogenic activation of the RAS/RAF signaling pathway impairs the response of metastatic colorectal cancers to anti-epidermal growth factor receptor antibody therapies. Cancer Research 67(6): 2643-2648.

Bermúdez-Humarán, L. G., Cortes-Perez, N. G., Lefèvre, F., Guimarães, V., Rabot, S., Alcocer-Gonzalez, J. M., Gratadoux, J. J., Rodriguez-Padilla, C., Tamez-Guerra, R.S., Corthier, G., Gruss, A., \& Langella, P. 2015. A novel mucosal vaccine based on live lactococci expressing E7 antigen and IL-12 induces systemic and mucosal immune responses and protects mice against human papillomavirus type 16-induced tumors. The Journal of Immunology 175(11): $7297-7302$.
BioLegend. 2018. Cell surface flow cytometry staining of whole blood. Available at bttps://mwn.biolegend.com/protocols/cellsurface-immunofluorescent-staining-of-whole-blood/4240/ (accessed 4 May 2018).

Buhrman, J. D., \& Slansky, J. E. 2013. Mimotope vaccine efficacy gets a "boost" from native tumor antigens. OncoImmunology 2(4): e23492.

Calder, P. C. 2013. Feeding the immune system. Proceedings of Nutrition Society 72(3): 299-309.

Carbone, L., Carbone, E. T., Yi, E. M., Bauer, D. B., Lindstrom, K. A., Parker, J. M., Austin, J. M., Seo, Y., Gandhi, A. D., \& Wilkerson, J. D. 2012. Assessing cervical dislocation as a humane euthanasia method in mice. Journal of the American Association for Laboratory Animal Science 51(3): 352-356.

Chaft, J. E., Litvak, A., Arcila, M. E., Patel, P., D'Angelo, S. P., Krug, L. M., Rusch, V., Mattson, A., Coeshott, C., Park, B., Apelian, D. M., Kris, M. G., \& Azzoli, C. G. 2014. Phase II study of the GI-4000 KRAS vaccine after curative therapy in patients with stage I-III lung adenocarcinoma harboring a KRAS G12C, G12D, or G12V mutation. Clinical Lung Cancer 15(6): 405-410.

da Silva Antunes, R., Paul, S., Sidney, J., Weiskopf, D., Dan, J. M., Phillips, E., Mallal, S., Crotty, S., Sette, A., \& Arlehamn, C. S. L. 2018. Definition of human epitopes recognized in tetanus toxoid and development of an assay strategy to detect ex vivo tetanus $\mathrm{CD}^{+}{ }^{+} \mathrm{T}$ cell responses. PLoS ONE 13(2): e0193382.

Dea-Ayuela, M. A., Rama-Iñiguez, S., Torrado-Santiago, S., \& Bolas-Fernandez, F. 2006. Microcapsules formulated in the enteric coating copolymer Eudragit L100 as delivery systems for oral vaccination against infections by gastrointestinal nematode parasites. Journal of Drug Targeting 14(8): 567-575.

Dechant, M., \& Valerius, T. 2001. IgA antibodies for cancer therapy. Critical Reviews of Oncology/Hematology 39(1-2): 69-77.

Diethelm-Okita, B. M., Okita, D. K., Banaszak, L., \& Conti-Fine, B. M. 2000. Universal epitopes for human $\mathrm{CD}^{+}{ }^{+}$cells on tetanus and diphtheria toxins. The Journal of Infectious Diseases 181(3): 1001-1009.

Divya, J. B., \& Nampoothiri, K. M. 2015. Encapsulated Lactococcus lactis with enhanced gastrointestinal survival for the development of folate enriched functional foods. Bioresource Technology 188: 226-230.

Fikes, J. 2004. Chapter 2: The rational design of T cell epitopes with enhanced immunogenicity. In: Handbook of Cancer Vaccines. Ed. Morse, M. A., Clay, T. M. and Lyerly H. K. pp. 11-17. New Jersey: Humana Press.

Foy, K. C., Wygle, R. M., Miller, M. J., Overholser, J. P., BekaiiSaab, T., \& Kaumaya, P. T. P. 2013. Peptide vaccines and peptidomimetics of EGFR (HER-1) ligand binding domain inhibit cancer cell growth in vitro and in vivo. The Journal of Immunology 191(1): 217-227.

Haigis, K. M. 2017. KRAS allelles: the devil is in the detail. Trends in Cancer 3(10): 686-69.

Hartley, M. L., Bade, N. A., Prins, P. A., Ampie, L., \& Marshall, J. L. 2015. Pancreatic cancer, treatment options, and GI-4000. Human Vaccines \& Immunotherapeutics 11(4): 931-937.

Herreros-Villanueva, M., Chen, C. C., Yuan, S. S., Liu, T. C., \& Er, T. K. 2014. KRAS mutations: analytical considerations. Clinica Chimica Acta 431: 211-220.

Hirayama, M., \& Nishimura, Y. 2016. The present status and future prospects of peptide-based cancer vaccines. International Immunology 28(7): 319-328.

Holo, H., \& Nes, I. F. 1989. High-frequency transformation, by electroporation, of Lactococcus lactis subsp. cremoris grown with glycine in osmotically-stabilized media. Applied and Environmental Microbiology 55(12): 3119-3123. 
Israr, B., Kim, J., Anam, S., \& Anjum, F. R. 2018. Lactic acid bacteria as vectors: a novel approach for mucosal vaccine delivery. Journal of Clinical \& Cellular Immunology 9(2): 548.

Jinesh, G. G., Sambandam, V., Vijayaraghavan, S., Balaji, K., \& Mukherjee, S. 2018. Molecular genetics and cellular events of K-Ras-driven tumorigenesis. Oncogene 37(7): 839-846.

Jørgensen, C. M., Vrang, A., \& Madsen, S. M. 2013. Recombinant protein expression in Lactococcus lactis using the P170 expression system. FEMS Microbiology Letters 351(2): 170178.

Kadam, P., \& Bhalerao, S. 2010. Sample size calculation. International Journal of Ayurveda Research 1(1): 55-57.

Kametani, Y., Miyamoto, A., Tsuda, B., \& Tokuda, Y. 2015. B cell epitope-based vaccination therapy. Antibodies 4(3): 225-239.

Kaumaya, P. T. P. 2015. A paradigm shift: Cancer therapy with peptide-based B cell epitopes and peptide immunotherapeutics targeting multiple solid tumor types: emerging concepts and validation of combination immunotherapy. Human V accines \& Immunotherapeutics 11(6): 1368-1386.

Kimoto, H., Nomura, M., Kobayashi, M., Mizumachi, K., \& Okamoto, T. 2003. Survival of lactococci during passage through mouse digestive tract. Canadian Journal of Microbiology 49(11): 707-711.

Knittelfelder, R., Riemer, A. B., \& Jensen-Jarolim, E. 2009. Mimotope vaccination - from allergy to cancer. Expert Opinion on Biological Therapy 9(4): 493-506.

Kumar, S. R., Prabakaran, M., Ashok Raj, K. V., He, F., \& Kwang, J. 2015. Amino acid substitutions improve the immunogenicity of $\mathrm{H} 7 \mathrm{~N} 7 \mathrm{HA}$ protein and protect mice against lethanl H7N7 viral challenge. PLoS ONE 10(6): $\mathrm{e} 0128940$.

Lei, H., Xu, Y., Chen, J., Wei, X., \& Lam, D. M. K. 2010. Immunoprotection against influenza $\mathrm{H} 5 \mathrm{~N} 1$ virus by oral administration of enteric-coated recombinant Lactococcus lactis mini-capsules. Virology 407(2): 319-324.

Li, Y., Yuan, S., \& Deng, J. 2016. Harnessing B cells for cancer immunotherapy. Journal of Medical Oncology and Therapeutics 1(1): 8-13.

Lipford, G. B., Bauer, S., Wagner, H., \& Heeg, K. 1995. In vivo CTL induction with point-substituted ovalbumin peptides: immunogenicity correlates with peptide-induced MHC class I stability. Vaccine 13(3): 313-320.

Lu, S., Jang, H., Muratcioglu, S., Gursoy, A., Keskin, O., Nussinov, R., \& Zhang, J. 2016. Ras conformational ensembles, allostery and signaling. Chemical Reviews 116(11): 6607-6665.

Ludvigsson, J. F., Neovius, M., Ye, W., \& Hammarström, L. 2015. IgA deficiency and risk of cancer: a population-based matched cohort study. Journal of Clinical Immunology 35(2): 182-188.

McCormick, F. 2015. KRAS as a therapeutic target. Clinical Cancer Research 21(8): 1797-1801.

McCormick, F. 2018. Targeting KRAS directly. Annual Review of Cancer Biology 2: 81-90.

Mestas, J., \& Hughes, C. C. W. 2004. Of mice and not men: Differences between mouse and human immunology. The Journal of Immunology 172(5): 2731-2738.

Mills, C. D., Kincaid, K., Alt, J. M., Heilman, M. J., \& Hill, A. M. 2000. M-1/M-2 macrophages and the Th1/Th2 paradigm. The Journal of Immunology 164(12): 6166-6173.

Ng, A. W. R., Tan, P. J., Hoo, W. P. Y., Liew, D. S., Teo, M. Y. M., Siak, P. Y., Ng, S. M., Tan, E. W., Raha, A. R., Lim, R. L. H., Song, A. A. L., \& In, L. L. A. 2018. In silico-guided sequence modifications of $\mathrm{K}$-ras epitopes improve immunological outcome against G12V and G13D mutant KRAS antigens. Peer] 6: e5056.

Nomura, M., Kimoto, H., Someya, Y., \& Suzuki, I. 1999. Novel characteristic for distinguishing Lactococcus lactis subsp. lactis from subsp. cremoris. International Journal of Systematic Bacteriology 49(1): 163-166.

Oryazún, P., \& Kobe, B. 2016. Recombinant and epitope-based vaccines on the road to the market and implications for vaccine design and production. Human Vaccines \& Immunotherapeutics 12(3): 763-767.

Palmer, D. H., Dueland, S., Valle, J. W., \& Aksnes, A. K. 2017. A phase I/II trial of TG01/GM-CSF and gemcitabine as adjuvant therapy for treating patients with resected RASmutant adenocarcinoma of the pancreas. [Abstract 4119] Journal of Clinical Oncology 35(15, Suppl 4119): 4119.

Pellissery, A. J., \& Nair, U. R. 2013. Lactic acid bacteria as mucosal delivery vaccine. Advances in Animal and Veterinary Sciences 1(6): 183-187.

Pogue, R. R., Eron, J., Frelinger, J. A., \& Matsui, M. 1995. Aminoterminal alteration of the HLA-A*0201-restricted human immunodeficiency virus pol peptide increases complex stability and in vitro immunogenicity. Proceedings of the National Academy of Sciences of the United States of America 92(18): 81668170.

Poquet, I., Saint, V., Seznec, E., Simoes, N., Bolotin, A., \& Gruss, A. 2000. HtrA is the unique surface housekeeping protease in Lactotoccus lactis and is required for natural protein processing. Molecular Microbiology 35(5): 1042-1051.

Prior, I. A., Lewis, P. D., \& Mattos, C. 2012. A comprehensive survey of Ras mutations in cancer. Cancer Research 72(10): 2457-2467.

Sahin, U., \& Türeci, Ö. 2018. Personalized vaccines for cancer immunotherapy. Science 359(6382): 1355-1360.

Sasan, H., Abdul Rahim, R., Foo, H. L., Radu, S., \& Hassan, M. D. 2011. Construction of vaccine from Lactococcus lactis bacteria using Aeromonas bydropbila virulent Aerolysin gene. Iranian Journal of Fisheries Sciences 10(1): 143-153.

Schreurs, M. W. J., Kueter, E. W. M., Scholten, K. B. J., Lemonnier, F. A., Meijer, C. J. L. M., \& Hooijberg, E. 2005. A single amino acid substitution improves the in vivo immunogenicity of the HPV16 oncoprotein E7(11-20) cytotoxic T lymphocyte epitope. Vaccine 23(31): 4005-4010.

Sharav, T., Wiesmüller, K. H., \& Walden, P. 2007. Mimotope vaccines for cancer immunotherapy. Vaccine 25(16): 3032 3037.

Shimizu, S. 2004. Chapter 32: Routes of Administration. In: The Laboratory Mouse (The Handbook of Experimental Animals). 1st edition. Ed. Hedrich H. pp. 527-541. Massachusetts: Academic Press.

Slingluff, C. L. 2011. The present and future of peptide vaccines for cancer: single of multiple, long or short, alone or in combination? The Cancer Journal 17(5): 343-350.

Song, A. A. L., In, L. L. A., Lim, S. H. E., \& Raha, A. R. 2017. A review on Lactococcus lactis: from food to factory. Microbial Cell Factories 16(1): 55.

Stephen, A. G., Esposito, D., Bagni, R. K., \& McCormick, F. 2014. Dragging Ras back in the ring. Cancer Cell 25(3): 272-281.

Subramaniam, M., Baradaran, A., Rosli, M. I., Rosfarizan, M., Khatijah, Y., \& Raha, A. R. 2012. Effect of signal peptides on the secretion of $\beta$-cyclodextrin glucanotransferase in Lactococcus lactis NZ9000. Journal of Molecular Microbiology and Biotechnology 22(6): 361-372.

Swaminathan, A., Lucas, R. M., Dear, K., \& McMichael, A. J. 2014. Keyhole limpet hemocyanin - a model antigen for human immunotoxicological studies. British Journal of Clinical Pharmacology 78(5): 1135-1142.

Vaickus, L. J., Bouchard, J., Kim, J., Natarajan, S., \& Remick, D. G. 2010. Inbred and outbred mice have equivalent variability in a cockroach allergen-induced model of asthma. Comparative Medicine 60(6): 420-426.

Yano, A., Ito, K., Miwa, Y., Kanazawa, Y., Chiba, A., Iigo, Y., Kashimoto, Y., Kanda, A., Murata, S., \& Makino, M. 2015. 
The peptide vaccine combined with prior immunization of a conventional diphtheria-tetanus toxoid vaccine induced amyloid $\beta$ binding antibodies on cynomolgus monkeys and guinea pigs. Journal of Immunology Research 2015: 786501.

Yuen, G., Demissie, E., \& Pillai, S. 2016. B lymphocytes and cancer: a love-hate relationship. Trends in Cancer 2(12): 747757.

Zarnitsyna, V. I., Ellebedy, A. H., Davis, C., Jacob, J., Ahmed, R., \& Antia, R. 2015. Masking of antigenic epitopes by antibodies shapes the humoral immune response to influenza. Philosophical Transactions of the Royal Society B Biological Sciences 370(1676): 20140248.

Zhang, X., Hu, S., Du, X., Li, T., Han, L., \& Kong, J. 2016. Heterologous expression of car- cinoembryonic antigen in Lactococcus lactis via LcsB-mediated surface displaying system for oral vaccine development. Journal of Microbiology, Immunology and Infection 49(6): 851-858. 